\begin{tabular}{|l|l|}
\hline Postprint Version & 1.0 \\
\hline Journal website & http://www.blackwell-synergy.com/loi/jan \\
Pubmed link & $\begin{array}{l}\text { http://www.ncbi.nlm.nih.gov/entrez/query.fcgi?cmd=Retrieve\&db=pubmed\&dop } \\
\text { t=Abstract\&list_uids=15117353\&query_hl=17\&itool=pubmed_docsum }\end{array}$ \\
\hline DOI & $10.1111 / \mathrm{j} .1365-2648.2004 .03031 . x$
\end{tabular}

Correspondence: Marco Algera, Populierenhof 64, 2411 TB Bodegraven, The Netherlands. E-mail: m.algera@filternet.nl

\title{
Home care needs of patients with long-term conditions: literature review
}

MARCO ALGERA MNSC RN

Researcher, Netherlands Institute for Health Services Research (Nivel), Utrecht, The Netherlands

ANNEKE L. FRANCKE PHD RN

Coordinator, Research Programme Nursing and Caring, Netherlands Institute for Health Services

Research (Nivel), Utrecht, The Netherlands

ADA KERKSTRA PHD

Head, Research Department, Netherlands Institute for Health Services Research (Nivel), Utrecht, The Netherlands

JOUKE VAN DER ZEE PHD

Professor, Director, Netherlands Institute for Health Services Research (Nivel), Utrecht, The Netherlands

Background. There is a widely felt need to improve the match between long-term patients' care needs and actual use of home care. As this match is not always adequate, it is important to know what factors influence it.

Aim. The aim of this paper is to provide insight into long-term patients' need and actual use of home care, and the factors influencing these.

Method. A literature review was carried out, based on database searches in Pub- Med, CINAHL and the Nivel online library catalogue. A total of 114 papers were retrieved, but only 13 clearly dealt with use of professional home care (rather than informal home care or residential care) by people with long-term conditions.

Results. There is a dearth of publications on factors influencing the match between care need and actual use of professional home care among people with long-term conditions. Most of the 13 publications reviewed concerned determinants of professional home care use, rather than the match between patients' felt needs and the home care delivered. From these studies, a profile of people with long-term conditions who used home care emerged. In general, older, non-white women, with multiple chronic diseases and impairments, and who had recently had inpatient care, tended to make more use of professional home care.

Conclusion. Future research in this field is recommended, particularly into systemand patientrelated characteristics that may be responsible for the mismatch between care need and use.

\section{BACKGROUND}

Until the mid-1990s, in the Netherlands and many other Western European countries, health care organizations were supply-centred: delivery of care was determined to a large extent by availability (Adam \& Hutten 2001). However, under the influence of movements for patient empowerment and emancipation, there has been an increase in the attention paid to patients' health care needs by decisionmakers and society at large. This has resulted in an emphasis on 'tailor-made care' with its 
implicit match between patients' need for care and care used. Nevertheless, in real life, 'tailor-made care' is not always supplied. Consequently, it is important for health care professionals and policymakers to gain insight into the factors that account for the care need/use mismatch. The primary aim of this paper is to provide this insight with regard to people with long-term conditions who need home care. Although a good match is essential for every group of patients, it is particularly important for this patient group. Because of the enduring, often complex, character of their illnesses, many of these patients are largely dependent on health care organizations and professionals for much of their lives, and many are heavy consumers of home care (Steel et al. 1998). This focus on long-term illness is also relevant, because, in the West, increasing numbers of people suffer from such diseases, a fact closely related to the ageing of the population (Philp 2001).

Despite the increasing importance of long-term illness and home care use in health policy, no systematic review of determinants of the need/use match in professional home care was found. This prompted the review presented in this paper, in which 'need for care' means patient-perceived need for care because of health-related deficits (Bradshaw 1972). 'Professional home care', in the context of this paper, means care delivered by nursing or caring professionals in patients' homes. This may include several types of care: care relating to instrumental activities of daily life (IADL-care), also called domestic care; care relating to activities of daily living (ADLcare), also called physical care or personal care; nursing care (often involving technical interventions); and psychosocial care.

\section{AIMS}

It was expected that the need/use match in professional home care would be related to characteristics of both people with long-term illness and the health care system. The primary research question addressed in this review of the literature was:

What patient characteristics and what health care system characteristics influence the match between need for care in people with longterm conditions and their actual use of professional home care?

However, in the initial phase of the review it became clear that there was very little literature on determinants of the match (or mismatch) between these patients' needs for home care and home care use. As it was expected that characteristics determining this match would be virtually identical to characteristics influencing home care use, a secondary research question was formulated:

What patient and health care system characteristics influence use of professional home care in patients' with long-term conditions?

\section{RESEARCH MODEL}

In developing a model that could structure the review of the literature presented, various concepts were derived from the Behavioural Model of Health Services Use (Andersen \& Newman 1973, Andersen 1995). In this well-known model, and the adapted model used in our study (see Figure 1), the characteristics of health care systems and patients are considered to be the main determinants of use of care. Health care system characteristics may be those of the organizations or the professionals who deliver care. In accordance with Andersen (1995), patient characteristics are differentiated into three categories:

- predisposing characteristics, such as age and gender, that may influence likelihood of using health care services;

- enabling resources, or patients' opportunities to use the health care system. Income, education, and type of health insurance have been noted as the most relevant factors;

- need factors, or the necessity of consuming health care services, often due to illness. Examples include impediments to instrumental activities of daily life, and pain and fatigue.

\section{[ FIGURE 1]}

In the Andersen and Newman model, patient and health care system characteristics impact on health care use. However, in our adapted model, it is assumed that these characteristics influence not only use, but also the match between need and actual use of home care (see Figure 1). 


\section{SEARCH METHODS}

In the review, a data search was carried out in the online catalogue of the Netherlands Institute for Health Services Research (Nivel) for the period 1980-2002, PubMed (1980- 2002), and CINAHL (1982-2002). Key search terms entered for question 1 were 'home care services', 'health services needs and demand', 'utilization', 'needs assessment', 'unmet need' and 'case management'. Key search terms entered for question 2 were: 'home care services', 'chronic disease', 'health services needs and demand' and 'utilization'. In both cases combinations of key words were entered.

The keywords and initial searches of the online databases produced a total of 862 potentially useful references. Subsequently, the abstracts and titles of these references were screened and only literature which met the following inclusion criteria was considered appropriate for review:

- the literature (published reports, papers or books) contains empirical research on (a) factors influencing the match between need and use of professional home care in patients with long-term conditions or (b) factors influencing use of professional home care in this patient group;

- it has a specific focus on people with long-term somatic conditions; and

- it is written in English, Dutch, German or French.

A total of 114 publications seemed to meet the inclusion criteria. However, after close reading of these, only 11 clearly met the criteria. After searching the reference lists of these, two further relevant publications were identified and included in the review, making a total of 13 (see Tables 1 and 2).

The main reasons for the ineligibility of many potentially useful references were that distinctions were not made between professional and non-professional care or home care and inpatient care (e.g. Van den Bos 1989, Mor et al. 1992), and between data from people with long-term conditions and data from other patient groups (e.g. Coulton \& Frost 1982, Evashwick et al. 1984, Kempen \& Suurmeijer 1991, Kerkstra \& Vorst-Thijssen 1991, Shaughnessy et al. 1994, Tennstedt et al. 1994).

\section{RESULTS}

\section{Description of the studies reviewed}

\section{Focus of the studies}

Studies reviewed focused on determinants of the match between need and use of home care among people with longterm conditions (Table 1), or determinants of home care use in this patient group (Table 2). One study addressed both types of determinants (Scholte op Reimer 1999) and is, thus, included in both Tables 1 and 2.

Types of professional home care included in the analyses varied among the studies. Some studies distinguished between several types of home care (e.g. IADL-care or ADL-care) or made a distinction based on type of home care provider involved (e.g. home care nursing or home help). Other publications reviewed, however, were not explicit about the kind of professional home care studied (Tables 1 and 2).

\section{[ TABLE 1 ]}

Four studies focused on determinants of use (or lack of use) of some kind of home care, and six publications only reported determinants of the amount or intensity of home care utilization (Table 2). Two studies (Fleishman 1997, Freiman \& Breen 1997) encompassed both focuses.

A wide range of chronic patient groups was included in the studies reviewed. The most frequently investigated patient groups were those with chronic heart failure (five studies), chronic obstructive pulmonary disease (COPD) (four studies), and diabetes mellitus, stroke and HIV/AIDS (three studies). Only one study focused on cancer, and one study on rheumatoid arthritis.

\section{Origin}

Ten of the 13 studies reviewed were carried out in the United States of America (USA), and three were conducted in the Netherlands (Tables 1 and 2).

\section{Methodological properties and qualities}


Eleven of the 13 studies featured quantitative analysis of survey data, sometimes combined with analysis of patient records (Tables 1 and 2). One study was based on records only (Adams \& Kramer 1996). One study had a non-randomized control group design and focused on the influence of a collaborative intervention by primary care professionals (Sommers et al. 2000).

The methodological quality of the two studies addressing the first research question (Table 1) was beyond dispute. Large research samples were used $(n=2832$ and 328) and the analysis methods (logistic regression analyses) seemed adequate.

However, methodological quality of the studies on the second research question varied as far as sample sizes were concerned. Most of these studies had fairly large research samples, while three had smaller ones $(n<150)$ (Table 2). In most of the studies, multiple logistic regression analyses were used; these appeared to be adequate for answering questions on the determinants of home care use.

\section{Characteristics influencing the match between need and use of professional home care}

An adequate match between chronic patients' need and use of care indicates that a care need was well met, while a poor match means that the need was not sufficiently met. This is coherent with the two relevant studies found, which described a mismatch in terms of 'unmet needs' (Scholte op Reimer 1999, Katz et al. 2000).

However, these two studies devoted their attention to the influence of patient characteristics and did not explore the influence of health care system characteristics. Both studies investigated the influence of predisposing characteristics such as age, gender and living arrangements (Table 1). The findings of these two studies did not, however, point in a clear direction. In Scholte op Reimer's study it was found that younger or male stroke patients had a larger probability of unmet home care needs, while in Katz et al.'s work age and gender did not appear to be influential (Table 1). In addition, in both studies, living arrangements (composition of the household) proved to have no significant influence.

In addition, both studies investigated the influence of education, an 'enabling resource'. In this regard, the studies did have comparable findings: neither found a significant relationship between education and unmet home care needs.

Both studies also explored whether there was a relationship between various need factors and unmet home care needs. However, the two studies did not include the same need factors, and so their results cannot be compared. For the influence of characteristics that were only considered in one of the two studies see Table 1.

\section{Health care system characteristics influencing use of professional home care}

Literature on the influence of health care system characteristics on use of home care by people with long-term conditions was also scarce. The few relevant studies focused on diverse characteristics and patient groups (De Haan et al. 1993, Kenney 1993, Sommers et al. 2000). Kenney described the influence of a broad variety of health care system characteristics on use of home care by patients with COPD, chronic heart failure or stroke, and found that the chance of using it increased when there were fewer nursing home beds or more health staff available per insured person. In addition, use of home care was greater if there were fewer hospitalbased long-term care arrangements or more hospitalowned home health agencies. All but one of these relationships appeared to be significant in patients with COPD and chronic heart failure (Table 2), whereas, in patients who had experienced stroke, only the relationship between a smaller number of nursing home beds per insured person and home care use appeared to be significant.

In the De Haan et al. (1993) study, it was found that if a general practitioner was notified about a stroke patient's discharge from hospital, the chance of home help use increased.

In a study involving a number of different diagnoses (Table 2), Sommers et al. (2000) detected no significant relationship between extent to which primary health care professionals (physicians, home care nurses and social workers) worked together and frequency of home care visits.

\section{[ TABLE 2 ]}

\section{Predisposing patient characteristics influencing use of professional home care}

Most of the studies reviewed considered the influence of the predisposing characteristics of people with long-term conditions on home care utilization (Table 2). The influence of age, gender, and living 
arrangements, in particular, were usually explored. As far as age was concerned, the results were almost unidirectional and tended to confirm expectations: the older the patient, the more likely it was that professional home care would be used (De Haan et al. 1993, Kenney 1993, Kane et al. 1994, Freiman \& Breen 1997, Riemsma et al. 1998, Scholte op Reimer 1999, London et al. 2001). For instance, in a longitudinal study, Scholte op Reimer reported that the odds on receiving IADL- or ADLcare five years after stroke was $8 Æ 4$ times higher among patients over the age 72 years than among younger respondents. Other studies, however, did not find unidirectional effects of age on home care use (Bull 1994, Freiman \& Breen 1997).

Most studies describing the effect of gender on home care utilization found that women used home care more often (De Haan et al. 1993, Kenney 1993, Fleishman 1997, Freiman \& Breen 1997, Riemsma et al. 1998, London et al. 2001). For instance, in a study of HIV patients, being female increased the odds of professional home care by $61 \%$ (London et al. 2001). However, in a minority of studies, no significant relationship was found between gender and use of home care. For example, in Kane et al.'s (1994) study of chronic heart failure, COPD and stroke, and Scholte op Reimer's (1999) study of stroke, gender was not influential.

Living arrangements, as a predisposing characteristic for people with long-term conditions using home care, have been well researched. However, the studies reviewed seemed to contradict one another. Some studies showed significantly greater home care use when patients were living alone (De Haan et al. 1993, Riemsma et al. 1998, Scholte op Reimer 1999), whereas others indicated that patients living with others used home care more (Ettner \& Weissman 1994, Kane et al. 1994, Freiman \& Breen 1997). Scholte op Reimer, for instance, calculated probability of receiving ADL- or IADLcare in patients who had experienced stroke and found that those living alone were at least five times more likely to use care than those living with other people. On the other hand, Ettner and Weissman showed that patients with AIDS living with a partner received an average of $26 Æ 8$ hours more professional home care than those living alone. Other studies have found no significant effects of living arrangements on home care utilization (Fleishman 1997, Freiman \& Breen 1997, London et al. 2001).

Several studies also included ethnicity as a characteristic which might influence home care utilization (Table 2). Most of these studies indicated that being non-white increased the chance of using home care, although this relationship seemed also to be dependent on the diagnosis. For instance, in Kane et al.'s (1994) study, non-white people with COPD made 32\% more use of home care facilities than white people, but among patients with heart failure or stroke patients no relationship was found. In another study, being non-white increased the chance of using home care in patients with COPD and stroke, but not in patients with heart failure (Kenney 1993). For use of home care according to other, infrequently investigated, predisposing characteristics see Table 2.

\section{Enabling resources influencing use of professional home care}

A relatively large number of studies explored the influence of enabling resources (such as type of insurance, income, availability of facilities, educational level and degree of urbanization) on home care use.

In studies carried out in the USA type of insurance was one of the independent variables. Three main types of insurance could be distinguished: (1) Medicaid insurance for people below a certain level of income; (2) Medicare insurance for older people; and (3) insurance through membership of a Health Maintenance Organization (HMO) [Health Insurance Association of America (HIAA) 1999]. These studies produced ambiguous results. In some studies type of insurance made no difference (Ettner \& Weissman 1994, Adams \& Kramer 1996), while in others the influence of insurance type appeared to be dependent on the specific type of home care (Fleishman 1997, Freiman \& Breen 1997, London et al.2001).

In most studies investigating the influence of income on use of home care, no significant relationships were found (De Haan et al. 1993, Bull 1994, Ettner \& Weissman 1994, Freiman \& Breen 1997, London et al. 2001). However, two studies showed a significant but contradictory relationship (Fleishman 1997, Riemsma et al. 1998). Riemsma et al.(1998) reported that patients with rheumatoid arthritis who had a low income made more use of professional home care. In contrast, Fleishman (1997) found that a higher income was associated with use of a home help in people who were HIV positive. 
Another enabling resource included in a great deal of research on home care utilization is educational level. In these studies, education proved not to be predictive of use of home care. Patient samples on which this conclusion was based, involved patients with AIDS or HIV (Fleishman 1997, London et al. 2001), stroke (Scholte op Reimer 1999), and rheumatoid arthritis (Riemsma et al. 1998).

Three studies also investigated urbanization as a possible predictor of use of home care. Two of these studies indicated that urbanization did not have any significant relationship with use or intensity of home care among patients with cancer and rheumatoid arthritis respectively (Freiman \& Breen 1997, Riemsma et al. 1998). In contrast, in Kenney's (1993) study a higher level of urbanization appeared to be related to increased use of home care among patients with COPD and heart failure.

Some additional enabling resources and their relationships with home care use are displayed in Table 2; all these variables were only mentioned once in the literature reviewed.

\section{Need factors influencing use of professional home care}

As already stated, need factors refer to patient characteristics which are often illness-related and make use of professional care necessary (Andersen 1995). A high proportion of the studies considered the influence of need factors on use of home care by people with long-term conditions (Table 2).

Four major categories of need factors emerged from the literature reviewed. The first category relates to the conditions experienced by patients. In some studies, the main diagnosis only was subject to analysis; in others co-morbidity was also studied. In studies that included only the principle diagnosis, no significant results were reported; this was the case in a study that compared different types of home care (Adams \& Kramer 1996) and one on the difference between non-users and heavy users of home care (Freiman \& Breen 1997). However, in a number of studies in which comorbidity was involved, several significant effects on home care use were revealed. For instance, De Haan et al. (1993) found, in patients who had experienced stroke, that those who also had dementia appeared to make use of home help more often than those not diagnosed with dementia. Riemsma et al. (1998) reported that, in general, co-morbidity and also longer disease duration led to more use of home care. Kenney (1993), on the other hand, found no relationship between co-morbidity and home care use among patients suffering from multiple illnesses.

The second category of need factors concerns impairments in terms of ADL or IADL. The results of most of the studies reviewed pointed in the same direction: having impairments may increase the use of home care. Significant relationships between impairments and utilization of home care were reported in the case of patients with heart failure (Bull 1994), diabetes mellitus (Bull 1994), COPD (Bull 1994), stroke (De Haan et al. 1993, Scholte op Reimer 1999), AIDS (Ettner \& Weissman 1994), HIV (Fleishman 1997), and cancer (Freiman \& Breen 1997). Most studies found that having more impairments increased the chance of using home care facilities (Table 2). For instance, Scholte op Reimer (1999) noted that, in stroke patients, inability to perform IADL and severe handicap led to a rise in the use of IADL- and ADL-care by a factor of 6-12.

A third category of need factors relates to patients' perceptions of their own health status. Some research on this topic has been undertaken by Scholte op Reimer (1999) and De Haan et al. (1993). In both research projects, no significant effects of self-assessed health or emotional distress on use of home care were found. Riemsma et al. (1998), however, found that low self-efficacy expectations in respect of coping with rheumatoid arthritis, poor self-reported health, fatigue and feelings of loneliness were associated with greater use of home care.

The fourth category of need factors contains aspects of past care use. London et al. (2001) showed that HIV-positive patients who had recently received residential care made greater use of home care; the odds for the first-mentioned group were $3 Æ 2$ times higher than those for the group who had not received such care during the past 6 months. Kenney (1993) found that postsurgery stroke patients used home care more often than patients who had not had surgery; while among patients with COPD and heart failure these relationships were not found. In their study on people with cancer, Freiman and Breen (1997) concluded that number of hospitalizations was associated with the use/lack of use of home care, but not with intensity of use. Fleishman (1997) had comparable findings when relating recent hospitalization to use and frequency of home help.

For details about the influence of less frequently investigated factors see Table 2. 


\section{DISCUSSION}

This review of the literature has focused on factors influencing the match between perceived care need and use of home care in people with long-term conditions. No published studies on the influence of health care system characteristics on this match were identified, and only two relevant studies that considered the influence of the characteristics of people with long-term conditions were found. The limited number of studies found, differences between the specific patient groups involved, and the sometimes-contradictory findings inhibit bold conclusions. In light of the attention paid to tailor-made and needs-led care by decision-makers and society as a whole, it is surprising that so few empirical data exist on determinants of the match between need and use of home care.

Because of the scarcity of studies on the need/use match, a secondary aim of our review was to identify factors relating to home care use by people with long-term conditions. This was based on the assumption that the same determinants may influence home care use and the match between need for and use of home care. Again, few studies were identified, and most of these only paid attention to the influence of patient characteristics, rather than health care system characteristics. Nevertheless, on the basis of Kenney's (1993) research, it might be expected that health care system characteristics, such as availability of other care facilities, affect patients' use of home care. It seems probable that these characteristics can also impact on whether or not chronic patients' needs for care are met.

Based on the studies on patient characteristics, a profile of patients with long-term conditions who are likely to use home care is beginning to emerge. Some reservation should be made, because these studies involved a variety of diagnosis- related groups, did not always have unanimous findings and were sometimes based on small samples. Nonetheless, the emerging profile may be summarized as follows: in general, older non-white women, with a number of simultaneous chronic illnesses, impaired in both instrumental and physical activities, and having recently made use of inpatient care tend to make more use of home care.

The effects of living arrangements, type of insurance and urbanization on home care use appeared to diverge considerably. Aplausible reason for the contradictory findings on living arrangements may be as follows: on the one hand, people with long-term conditions who live alone may use professional home care because informal care may be unavailable; on the other hand, the presence of a partner or other informal caregiver may increase likelihood of using home care because they may help to arrange and co-ordinate it. Ettner and Weissman (1994) argue that fellow residents may also share the costs of professional home care, thus making use possible.

Remarkably enough, 10 of the 13 studies reviewed were conducted in the USA and three in the Netherlands. This is all the more remarkable in light of the use of several international literature databases, and the application of a selection criterion indicating that, in addition to English and Dutch, publications in German or French could be included. The finding that the majority of relevant studies were of US origin may indicate that, in the USA, research on this topic is performed more frequently and more highly developed. However, it may also point to a publication bias. For instance, Dickersin (1990) suggests that, when a manuscript is submitted to an English language journal and the author's native language is not English, bias may occur. Publication of 'second language' papers may be especially problematic if no significant findings are being reported.

\section{LIMITATIONS OF THE STUDY}

This literature review was conducted as part of a broader research project in which the match between the felt care needs of people with long-term conditions, their care needs as identified by an assessment agency, and the home care delivered was studied. When searching the literature for possible determinants of this match, the research questions had to be strict, and papers in which results could not be clearly attributed to use of professional home care had to be discarded. This could be because results for professional home care were combined with those on informal home care or residential care. An even greater number of studies did not differentiate between chronic and acute diseases, and, thus, were not included. If the research questions addressed in this review had not been 'dictated' by the broader research project, more papers, especially those on home care use in acute conditions, could have been included, making the profile of 'the' home care user more solid. 


\section{IMPLICATIONS FOR NURSING}

The results of this study are informative for professionals engaged in home nursing, and give insight into patient characteristics that are associated with use of home care. A profile of 'the' home care user emerged which describes, in general terms, the people who are likely to make use of professional home care. However, the profile also draws the attention of nurses, policymakers in nursing, and needs assessors to patients who do not match this profile. It is not surprising that patients who do not satisfy the need-related determinants of home care use make less use of professional home care. However, younger and/or white men appear to have difficulty in making use of home care at all or in making intense use of it, and these groups of patients should be given extra attention in meeting their home care needs. In regions in which certain features of the health care system - such as extended inpatient care facilities - are not present, the availability of home care should be given priority. This may be the case for some chronic Diagnosis Related Group rather than the other. The professional standards of both home care staff and needs assessors should lead to needs-led home care provision, in that professional home care provision should meet patients' needs. However, to date, determinants of the match between need and professional home care delivery are not evidence-based.

\section{WHAT IS ALREADY KNOWN ABOUT THIS TOPIC}

- People with long-term conditions are heavy users of home care.

- In practice, home care provision does not always match the needs of people with longterm conditions.

\section{WHAT THIS PAPER ADDS}

- Insight into determinants of the use of home care by people with long-term conditions.

- Insight into 'the state of the art' in research on determinants of the match between care needs and use by people with long-term conditions.

\section{CONCLUSION}

This review of literature has disclosed several gaps in existing knowledge. These gaps are greatest with respect to factors responsible for an adequate/poor match between felt need for and use of home care in people with long-term conditions. In addition, little is known about the specific influence of health care system characteristics on home care use in this patient group.

In the broader research project, of which this literature review is the first phase, efforts will be made to fill the knowledge gap on factors that influence the match between need for and actual use of professional home care. Attention will also be paid to the influence of characteristics of the health care system and, more specifically, to the characteristics of assessment agencies and home care organizations in relation to those of patients with long-term conditions.

\section{ACKNOWLEDGEMENT}

This research project was funded by Netherlands Organization of Scientific Research (NWO-ZOB) research programme on care and social support for chronically ill patients. 


\section{TABLES AND FIGURES}

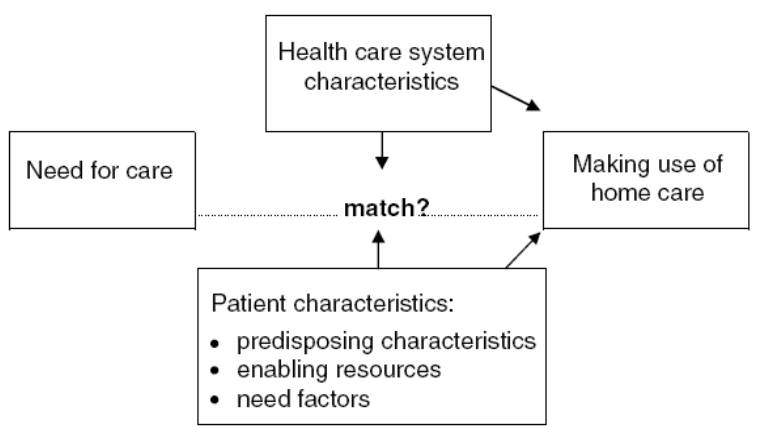

Figure 1 Characteristics influencing use of home care and the match between need and use.

Table 1 Studies on factors influencing the match between need and use of professional home care by people with long-term conditions

\begin{tabular}{|c|c|c|c|c|}
\hline $\begin{array}{l}\text { Author and year } \\
\text { Methodological characteristics } \\
\text { Country }\end{array}$ & $\begin{array}{l}\text { Health care system } \\
\text { characteristics }\end{array}$ & $\begin{array}{l}\text { Predisposing } \\
\text { characteristics }\end{array}$ & $\begin{array}{l}\text { Enabling } \\
\text { resources }\end{array}$ & Need factors \\
\hline $\begin{array}{l}\text { Katz et al. } 2000 \\
\text { Multiple logistic regression } \\
\text { analysis on survey data on } \\
2832 \text { HIV-infected patients } \\
\text { USA }\end{array}$ & - & $\begin{array}{l}\text { Unmet home care need } \\
\text { Age (NS) } \\
\text { Gender (S) } \\
\text { Ethnicity (NS) } \\
\text { HIV risk group (NS) } \\
\text { Past drug use (NS) } \\
\text { Living arrangements (NS) } \\
\text { Not living in own house (S) }\end{array}$ & $\begin{array}{l}\text { Unmet home } \\
\text { care need } \\
\text { Education (NS) } \\
\text { Income (NS) } \\
\text { Insurance (NS) } \\
\text { Not having a } \\
\text { case manager (S) }\end{array}$ & $\begin{array}{l}\text { Unmet home care need } \\
\text { Sum of needs (NS) } \\
\text { Higher lymphocyte } \\
\text { count (S) }\end{array}$ \\
\hline $\begin{array}{l}\text { Scholte op Reimer } 1999 \\
\text { Logistic regression analysis on } \\
\text { longitudinal survey data and } \\
\text { record data on } 382 \text { stroke patients } \\
\text { The Netherlands }\end{array}$ & - & $\begin{array}{l}\text { Unmet IADL and } \\
\text { ADL need } \\
\text { Younger age (S) } \\
\text { Male (S) } \\
\text { Living arrangements (NS) } \\
\text { Living independently (S) }\end{array}$ & $\begin{array}{l}\text { Unmet IADL } \\
\text { and ADL need } \\
\text { Education (NS) } \\
\text { Degree of } \\
\text { urbanization (NS) }\end{array}$ & $\begin{array}{l}\text { Unmet IADL } \\
\text { and ADL need } \\
\text { No dementia (S) } \\
\text { Less impaired (S) } \\
\text { Perceived health (NS) } \\
\text { Less emotional distress (S) }\end{array}$ \\
\hline
\end{tabular}

IADL, instrumental activities of daily life; ADL, activities of daily life; S, statistically significant; NS, not statistically significant. 


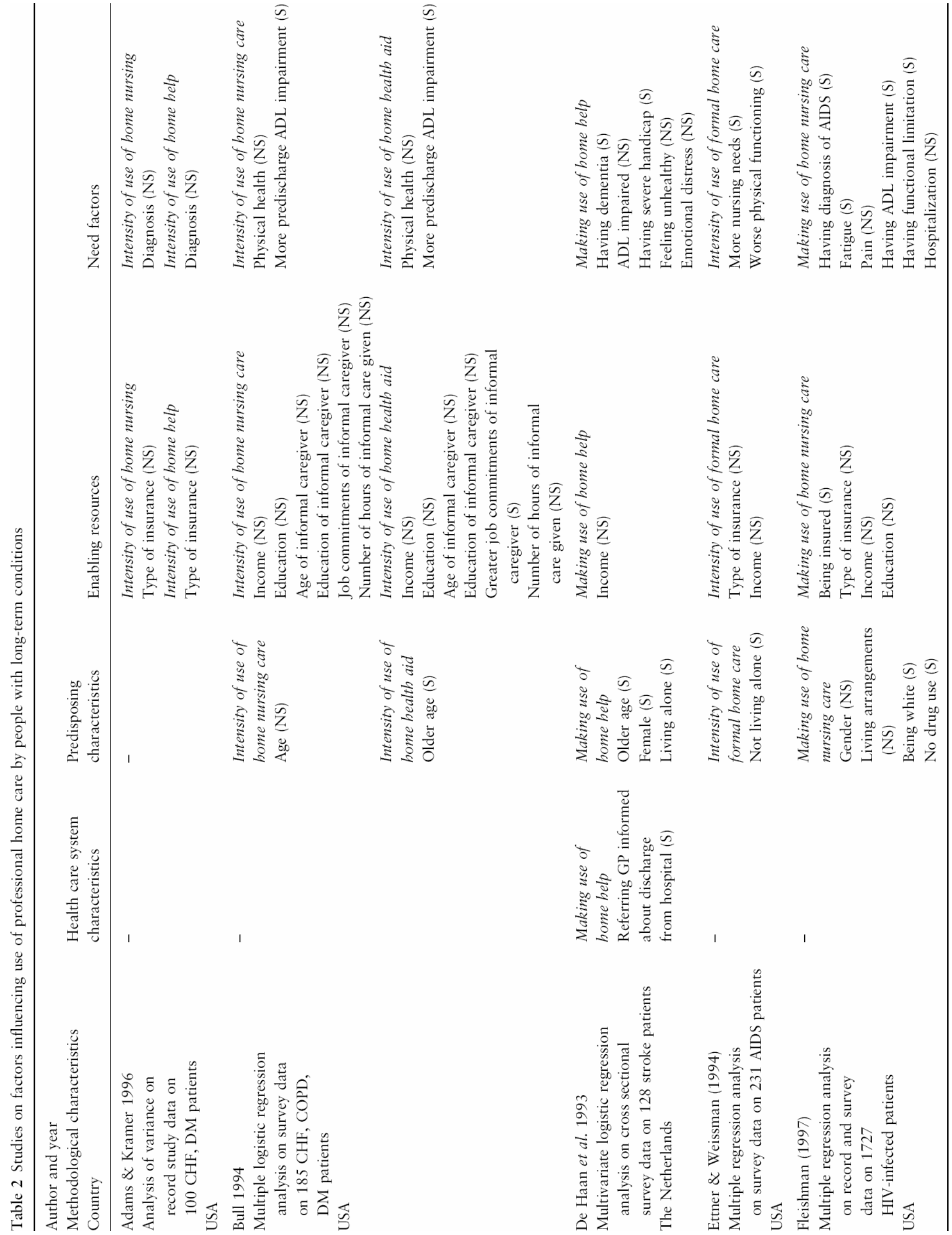




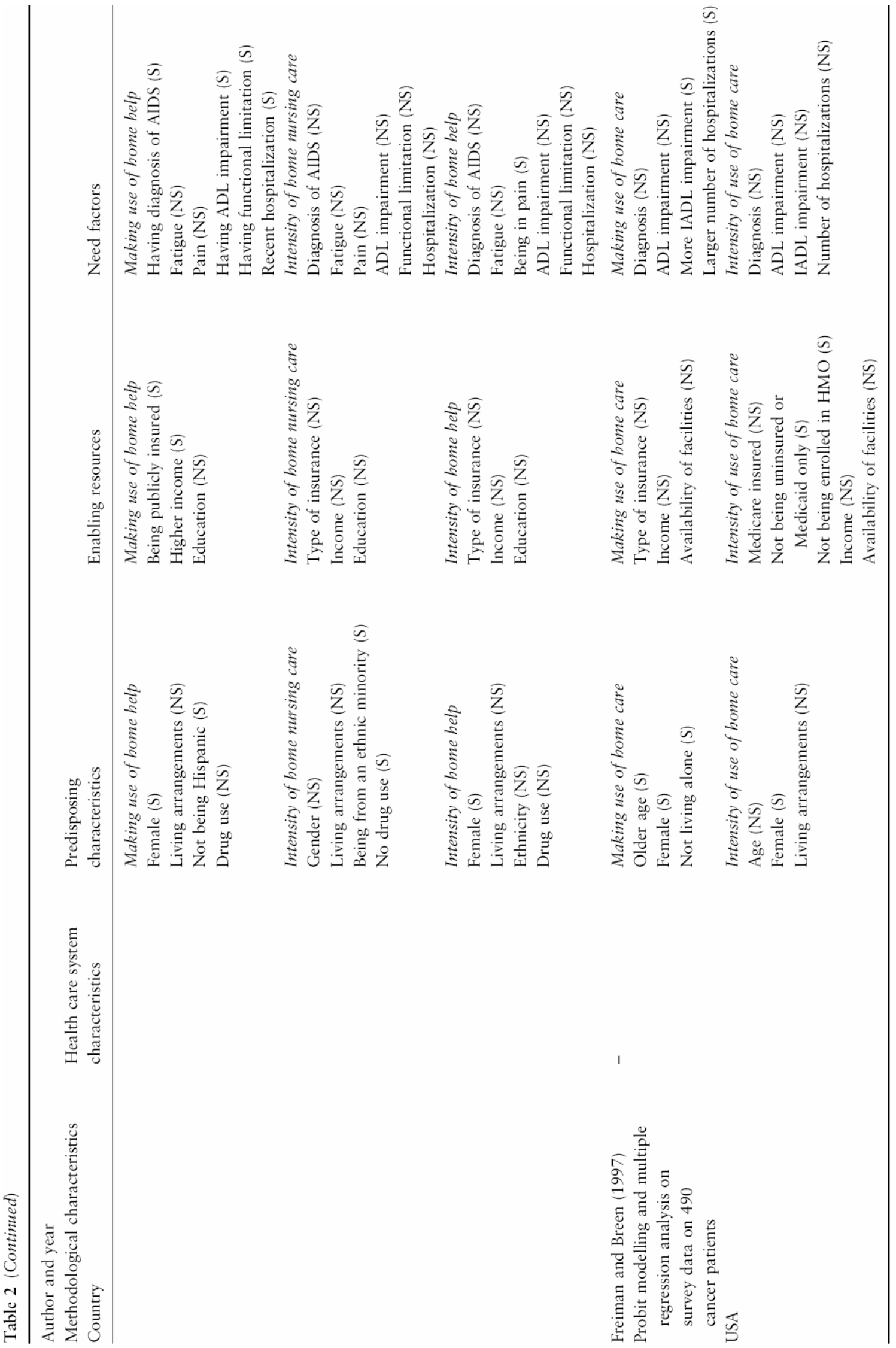



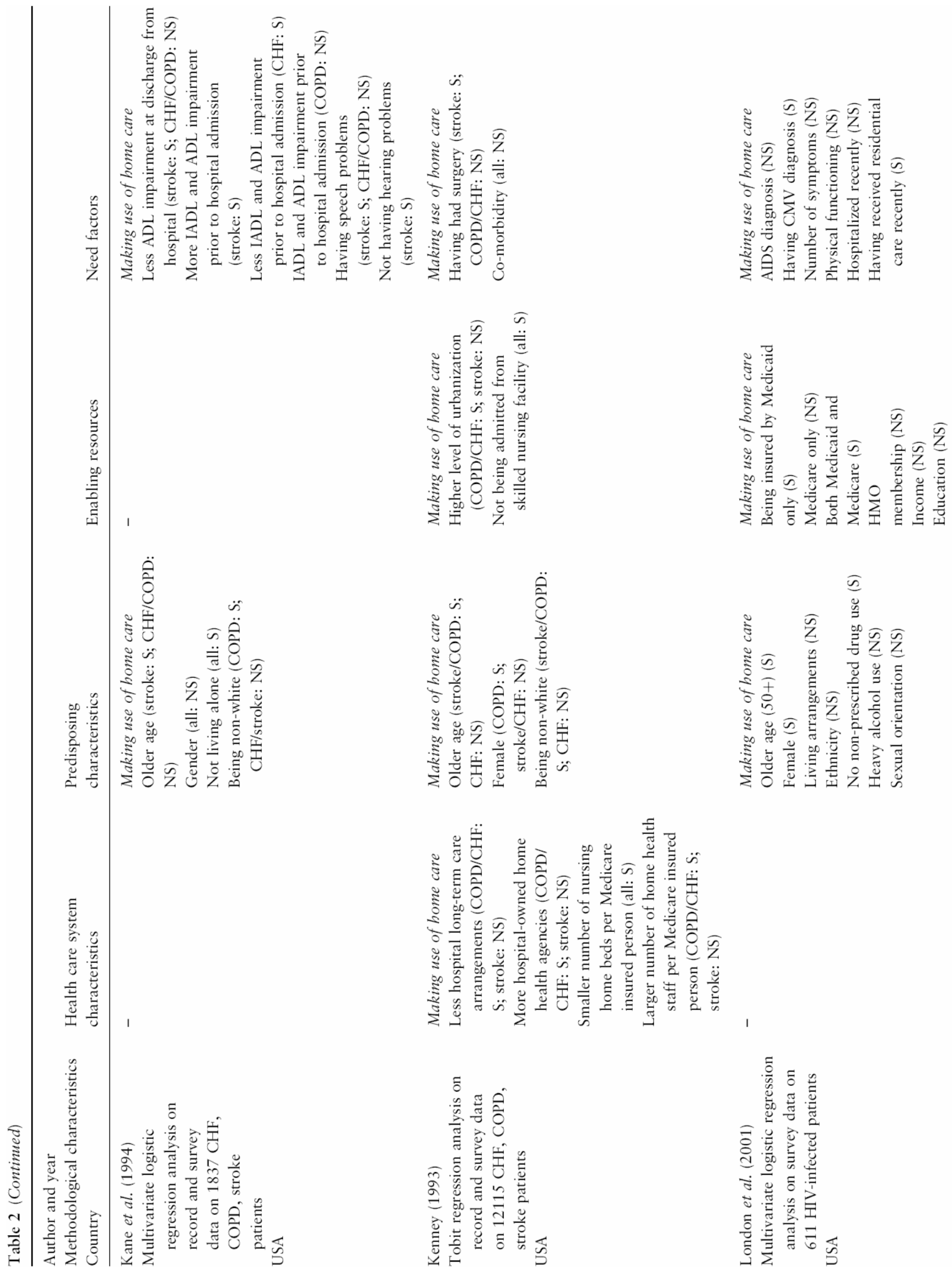


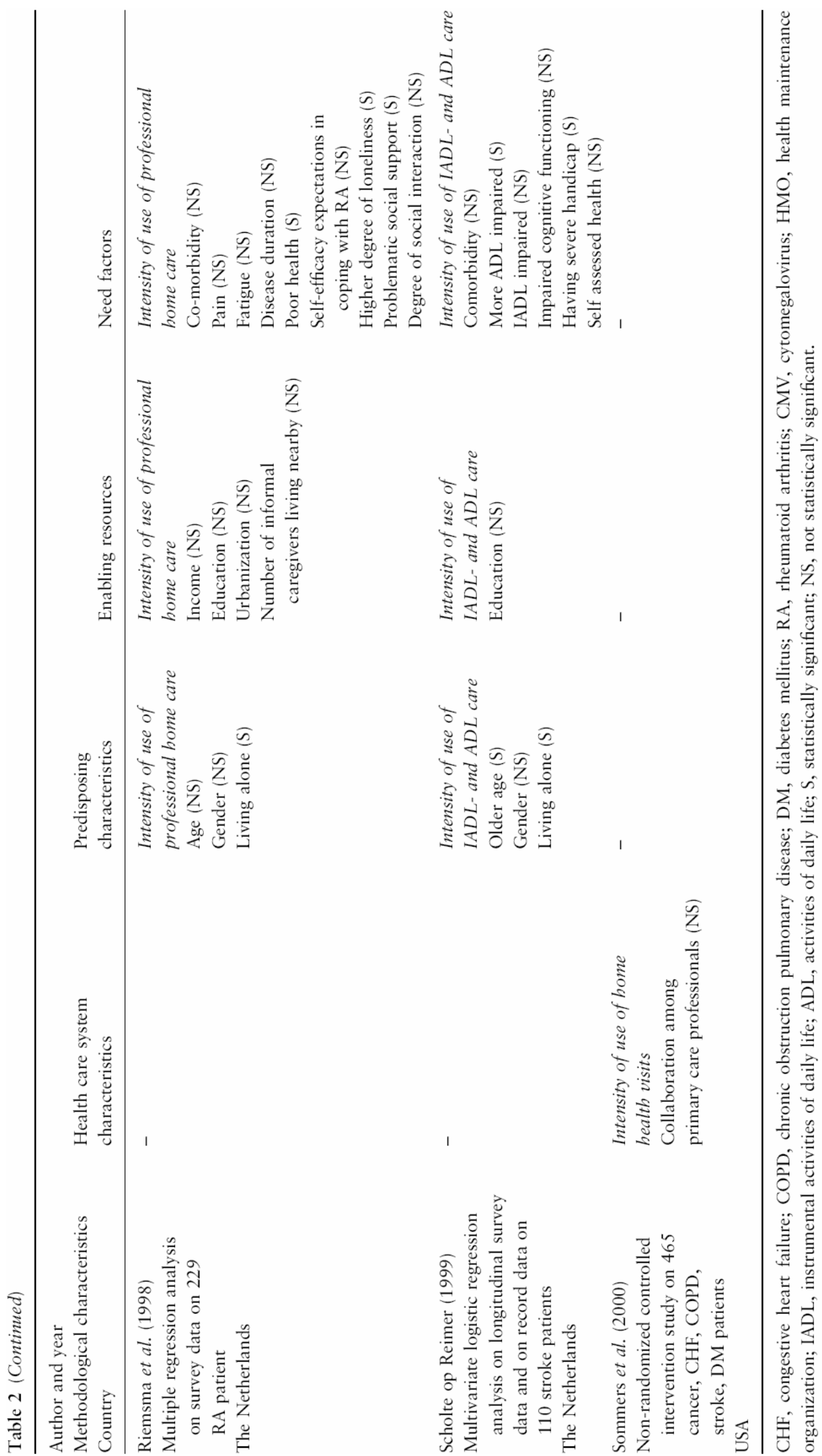




\section{REFERENCES}

Adam S.G.M. \& Hutten J.B.F. (2001) The Netherlands. In: Family Care of Older People in Europe (Philp I., ed.). IOS Press, Amsterdam/Berlin/Oxford/Tokyo/Washington DC, pp. 135-160.

Adams C.E. \& Kramer S. (1996) Home health resource utilization; health maintenance organization versus fee-for-service subscribers. Journal of Nursing Administration 26, 20-27.

Andersen R.M. (1995) Revisiting the behavioral model and access to medical care: does it matter? Journal of Health and Social Behavior 36, 1-10.

Andersen R. \& Newman J.F. (1973) Societal and individual determinants of medical care utilization in the United States. The Milbank Memorial Fund Quarterly Health and Society 51, 95-124.

Bradshaw J. (1972) A taxonomy of social need. In Problems and Progress in Medical Care (MacLachlan G., ed.). University Press, Oxford, pp. 69-82.

Bull M.J. (1994) Use of formal community services by elders and their family caregivers 2 weeks following hospital discharge. Journal of Advanced Nursing 19, 503-508.

Coulton C. \& Frost A.K. (1982) Use of social and health services by the elderly. Journal of Health and Social Behavior 23, 330-339.

De Haan R., Limburg M., Van der Meulen J. \& Van den Bos G.A.M. (1993) Use of health care services after stroke. Quality in Health Care 2, 222-227.

Dickersin K. (1990) Existence of publication bias and risk factors for its occurrence. Journal of the American Medical Association 263, 1385-1389.

Ettner S.L. \& Weissman J. (1994) Utilization of formal and informal home care by AIDS patients in Boston: a comparison of intravenous drug users and homosexual males. Medical Care 32, 459-470.

Evashwick C., Rowe G., Diehr P. \& Branch L. (1984) Factors explaining the use of health care services by the elderly. Health Services Research 19, 357-382.

Fleishman J.A. (1997) Utilization of home care among people with HIV infection. Health Services Research 32, 155-175.

Freiman M.P. \& Breen N. (1997) The use of home care by cancer patients: a multivariate analysis. Home Health Care Services Quarterly 16, 3-19.

Health Insurance Association of America (HIAA) (1999) Source Book of Health Insurance Data. HIAA, Washington, DC.

Kane R.L., Finch M., Chen Q., Blewett L., Burns R. \& Moskowitz M. (1994) Post-hospital home health care for Medicare patients. Health Care Financing Review 16, 131-153.

Katz M.H., Cunningham W.E., Mor V., Andersen R.M., Kellogg T., Zierler S., Crystal S.C., Stein M.D., Cylar K., Bozzette S.A. \& Shapiro M.F. (2000) Prevalence and predictors of unmet need for supportive services among HIV-infected persons: impact of case management. Medical Care 38, 58-69.

Kempen G.I.J.M. \& Suurmeijer Th.P.B.M. (1991) Professional home care for the elderly: an application of the Andersen-Newman model in The Netherlands. Social Science and Medicine 33, 1081- 1089.

Kenney G.M. (1993) How access to long-term care affects home health transfers. Journal of Health Politics, Policy and Law 18, 937-965.

Kerkstra A. \& Vorst-Thijssen T. (1991) Factors related to the use of community nursing services in the Netherlands. Journal of Advanced Nursing 16, 47-54.

London A.S., Fleishman J.A., Goldman D.P., McCaffrey D.F., Bozzette S.A., Shapiro M.F. \& Leibowitz A.A. (2001) Use of unpaid and paid home care services among people with HIV infection in the USA. AIDS Care 13, 99-121.

Mor V., Allen S.M., Siegel K. \& Houts P. (1992) Determinants of need and unmet need among cancer patients residing at home. Health Services Research 27, 337-360.

Philp I. (ed.) (2001) Family Care of Older People in Europe. IOS Press, Amsterdam/Berlin/Oxford/Tokyo/Washington DC.

Riemsma R.P., Klein G., Taal E., Rasker J.J., Houtman P.M., Van Paassen H.C. \& Wiegman O. (1998) The supply of and demand for informal and professional care for patients with rheumatoid arthritis. Scandinavian Journal of Rheumatology 27, 7-15.

Scholte op Reimer W.J.M. (1999) Long-term Care after Stroke: Studies on Care Utilisation, Quality of Care and Burden of Caregiving. PhD Thesis, University of Amsterdam, Amsterdam.

Shaughnessy P.W., Schlenker R.E. \& Hittle D.F. (1994) Home health care outcomes under capitated and fee-for-service payment. Health Care Financing Review 16, 187-222.

Sommers L.S., Marton K.I., Barbaccia J.C. \& Randolph J. (2000) Physician, nurse, and social worker collaboration in primary care for chronically ill seniors. Archives of Internal Medicine 160, 1825-1833. 
Algera, M., Francke, A.L., Kerkstra, A., Zee, J. van der

Home care needs of patients with long-term conditions: literature review.

Journal of Advanced Nursing: 46, 2004, nr. 4, p. 417-429

Steel K., Leff B. \& Vaitovas B. (1998) A home care annotated bibliography. Journal of the American Geriatrics Society 46, 898-909.

Tennstedt S., McKinlay J. \& Kasten L. (1994) Unmet need among disabled elders: a problem in access to community long-term care? Social Science and Medicine 38, 915-924.

Van den Bos G.A.M. (1989) Zorgen Van en Voor Chronisch Zieken (Concerns of and Caring for the Chronically III). Bohn, Scheltema and Holkema, Utrecht. 